\title{
La cobertura informativa del terremoto de Lorca en España: la responsabilidad social del periodista
}

institucional.us.es/ambitos/

\section{Marcos Mayo}

Universidad Complutense de Madrid

mmayocubero@gmail.com

\author{
Eva Lavín \\ Universidad Camilo José Cela \\ elavin@ucjc.edu
}

\section{Jorge Gallardo-Camacho}

Universidad Camilo José Cela

jgallardo@ucjc.edu

English Version: The information coverage of the earthquake of Lorca in Spain: the social responsibility of the journalist.

\begin{abstract}
Resumen
El artículo analiza la cobertura informativa del terremoto de Lorca cuantificando la presencia de estas noticias en El País y El Mundo a partir de un análisis de contenido de 91 artículos. Concluiremos que el interés por el terremoto desaparece casi en su totalidad a partir del quinto día en los medios analizados. También observaremos que la descoordinación en la comunicación pública en las distintas instituciones involucradas en la gestión de la catástrofe hizo que se cometieran errores que acabaron con la publicación de datos inexactos. Proponemos además una perspectiva ética sobre el tratamiento de este tipo de informaciones.
\end{abstract}

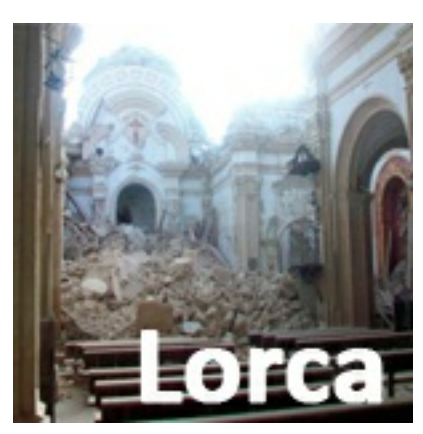

\section{Palabras clave}

Catástrofe, desastre, crisis, terremoto de Lorca, comunicación pública.

The paper analyzes the news coverage of the earthquake in Lorca quantifying the presence of this topic news in the newspapers EI País and El Mundo from the analysis of 91 articles. We conclude that interest in the earthquake disappears almost entirely from the fifth day in the media analyzed. We also observe that the lack of coordination on public communication in the differents public institutions involved in the disaster management, made mistakes that ended with the publication of inaccurate data is committed. We also propose an ethical perspective on the treatment of this type of information.

Keywords

Catastrophe, disaster, crisis, Lorca's earthquake, public communication.

\section{INTRODUCCIÓN: LA COMUNICACIÓN DEL RIESGO}

La comunicación del riesgo tiene una doble condición en el campo de las Ciencias Sociales, una práctica y otra como disciplina de investigación. Es, por tanto, un proceso enmarcado dentro del análisis de los riesgos con dos áreas relacionadas: por un lado, la evaluación de los riesgos enfocada en la identificación y valoración de los peligros potenciales del entorno; y por otro, la gestión de ese riesgo potencial que incluye los procesos de toma de decisiones, mitigación y comunicación (Slovic y Weber, 2002). 
Como disciplina de investigación, la comunicación del riesgo estudia los actores, los procesos, los mensajes y los efectos de esa comunicación. Un repaso de la bibliografía científica nos lleva a la década de 1950 cuando comienza el interés académico por esta disciplina en EE.UU. Ejemplo paradigmático es la campaña "Átomos por la paz" diseñada por el presidente Eisenhower. El objetivo de esta campaña política era eliminar el estigma negativo asociado a la energía nuclear, transmitiendo un mensaje al público general de desmilitarización y posibles usos civiles de la misma. Esto despertó el interés de los investigadores sociales que se propusieron estudiar las respuestas de la audiencia hacia ese nuevo empleo de la energía nuclear que no fuera militar (Kasperson y Stallen, 1991). Los primeros estudios se fundamentaron en la tesis de que el público hace valoraciones irracionales de los riesgos basadas en factores exógenos (emocionales) y no en factores racionales basados en el cálculo estadístico. Es entonces cuando aparece una corriente científica convencida de la necesidad de educar al público con el objetivo de que pudiera evaluar los riesgos adecuadamente desde la racionalidad. Así, la comunicación de riesgos se origina como un estudio complementario a las investigaciones sobre la percepción social del riesgo (Puy y Cortés, 1998).

Los movimientos antinucleares de la década de los 70 y sobre todo los accidentes de la central industrial de Seveso (Italia) en 1976 y de la central nuclear Three Mile Island en el estado de Pensilvania (EE.UU.) en 1979 provocaron un cambio de paradigma en los estudios de la comunicación de catástrofes por medio de la integración del factor de influencia de los medios de comunicación social. A partir de ahí, los investigadores pretenden confirmar la hipótesis de que el público valora el riesgo de acuerdo a factores subjetivos, pero añaden un factor determinante al aseverar que estos, al contrario de lo que se había defendido hasta el momento, no eran siempre irracionales. Finalmente, se concluye que en ese conjunto de factores se incluyen emociones, sistemas de creencias y valores socioculturales, pero también mensajes procedentes de los medios. Este contexto social coincide además con el aumento de la cobertura mediática de grandes catástrofes naturales y desastres tecnológicos (Lopera, 2011).

En España, la comunicación del riesgo se sustenta en varias agencias que dependen del Ministerio competente y que tienen la obligación de comunicar a la población sobre los diferentes riesgos específicos. En los años 80 , la creación pionera del Consejo de Seguridad Nuclear vino determinada por su obligación de informar sobre emergencias nucleares y radiológicas (BOE, 1980). La Dirección General de Protección Civil y Emergencias, adscrita al Ministerio del Interior, y encargada de informar de los peligros derivados de las catástrofes, crisis y emergencias fue creada en 1960 y desapareció como Dirección General en 1967. Promulgada la Constitución Española la Protección Civil reaparece en el organigrama estatal. La visita del Papa y la celebración del mundial de fútbol en España de 1982 sirvieron de impulso para dar a conocer el concepto de protección civil a la sociedad española (Ibáñez, 2012).

Numerosos autores destacan la falta de consenso entre los expertos para lograr una definición de comunicación del riesgo que pueda ser aplicada en todos los casos (Lopera, 2011). Algunos autores como Covello, Slovic y Von Winterfeldt (1986) consideran que es el intercambio de información sobre los riesgos ambientales y para la salud, el significado de los mismos y las decisiones tomadas para su gestión. Otway (1990) es más genérico al afirmar que es una comunicación unidireccional que alerta a la audiencia sobre los riesgos a los que se exponen. Por el contrario, Chatier y Gabler (2001) entienden que es una comunicación bidireccional que incluye los mensajes e interacciones relacionadas con las decisiones sobre los riesgos (noticias, anuncios, advertencias e instrucciones) que se comunican desde fuentes expertas hacia las audiencias inexpertas pero también al contrario. Sandman (1994) expone que lo que intenta es crear un nivel de alarma que se ajuste al nivel de gravedad del peligro que se comunique, especialmente cuando los mensajes procedan de la administración pública que tienen a mostrar que todo está bajo control.

La mayor parte de los estudios realizados sobre la comunicación del riesgo responden a las necesidades prácticas de los expertos al servicio de los gobiernos o de las empresas. Para este tipo de comunicación se emplean herramientas y metodologías propias del marketing, las relaciones públicas y la publicidad que presuponen que el objetivo es mantener un flujo de información entre emisor y receptor y que su éxito depende de la recepción del mensaje (Kasperson y Stallen, 1991). En cambio, en cuanto al trabajo periodístico en los escenarios de catástrofes y de emergencias podemos observar que la práctica profesional es a menudo objeto de críticas (Rodríguez y Odriozola, 2012; Orbe, 2012; Serrano, 2013). Los medios de comunicación, en ocasiones, elaboran informaciones sesgadas o distorsionadas de la realidad en contextos de catástrofes y 
emergencias. Algunas de estas prácticas periodísticas han sido ampliamente documentadas por diferentes investigadores (De Pablos y Elías, 2003; Lozano, 2003; González Villariny, 2008; Vicente-Mariño, 2009; Oyanedel y Alarcón, 2010; Odriozola, 2011; García y Nicasio, 2012; Ibáñez, 2014).

En diversos estudios sobre el tratamiento informativo de los desastres se ha observado una tendencia a orientar la información hacia el evento en sí, es decir, hacia los aspectos más llamativos o sensacionalistas del acontecimiento minimizando las explicaciones de los expertos que podrían brindar una versión más certera de lo sucedido. Las catástrofes no son sólo un fenómeno agudo como un terremoto o un huracán, sino que en realidad son la consecuencia de un fracaso (Arcos, 2015; UNISDR, 2011). Además se apunta a que también hay crisis crónicas olvidadas, no sólo catástrofes naturales puntuales y es responsabilidad de los medios informar sobre ellas (López, 2015). Es importante matizar que la responsabilidad social del periodista es aún más visible en la comunicación de catástrofes y que, en ocasiones, se produce un cierto relajamiento en los criterios éticos y deontológicos por el hecho de que los desastres naturales ocurren a miles de kilómetros de las redacciones.

En su investigación, Rodríguez y Odriozola (2012) perfilan una radiografía de la cobertura periodística de las catástrofes:

1. Predomina lo espectacular sobre la información. Según Lozano (2009) los medios generalmente no aportan información rigurosa.

2. Es imprescindible actuar con sensibilidad, empatía y rigor informativo a la hora de cubrir una catástrofe. Los detalles escabrosos sólo revictimizan a los afectados sin aportar información de calidad.

3. El hecho de que el periodista identifique el aspecto más llamativo hace que los consumidores de información experimenten sin ser víctimas y se produzca según Lozano (2009: 3) "una hipocondría generalizada".

4. Los datos contrastados y fiables se obtienen con el paso del tiempo, coincidiendo con la pérdida de interés y espacio de estas informaciones en los medios de comunicación y "el consumismo de sensaciones prima sobre el interés por conocer y comprender" (Rodríguez y Odriozola, 2012: 580).

Esto se observa en el ciclo de las noticias sobre catástrofes que se repite de forma cíclica con una tendencia común. La pérdida de interés informativo por la saturación de contenidos no hace desaparecer el problema, de ahí, que el desinterés de los medios demuestre su incapacidad para llevar a cabo una configuración informacional de acuerdo a los parámetros éticos que demanda el periodismo (Larrondo, 2006).

\subsection{Objetivo de la investigación}

El objetivo general de esta investigación es estudiar la cobertura periodística en el terremoto de Lorca en 2011. Para ello planteamos dos objetivos específicos:

O1. Comprobar si el ciclo de vida de las noticias de alto impacto como la catástrofe de Lorca es de cinco días como aseguran Hodgkinson y Stewart (1991).

O2. Analizar el tratamiento comunicativo del terremoto (a través del contenido de las noticias y de la opinión de los profesionales que participaron en el proceso informativo). En sentido, queremos extraer las lecciones aprendidas por los periodistas que cubrieron la catástrofe.

\section{METODOLOGÍA}

Para cumplir los objetivos planteados en la investigación nos centraremos en dos aspectos: por un lado, en el análisis del tratamiento informativo en los medios; y por otro, en las opiniones y experiencias de las personas que participaron en el proceso informativo de la comunicación de riesgo del terremoto de la localidad de Lorca, Murcia (España).

En el ámbito de los medios a observar recurrimos a una metodología basada en el análisis de los artículos del terremoto en dos de los diarios de mayor difusión en España, según el Estudio General de Medios (EGM) de 
2015, El País y El Mundo, durante el 12 y el 17 de mayo de 2011. La muestra nos da un total de N=91 artículos durante ese periodo (nos centramos en la prensa escrita y no en la prensa digital ya que nos permitirá cuantificar de una manera más estable los índices que planteamos a continuación). De esta manera, para cuantificar la relevancia de la cobertura periodística hemos empleado dos índices. Uno que mide el porcentaje de espacio que ocupa la noticia en la portada (que es elaborada y supervisada directamente por el director del periódico y en ella se publican únicamente las noticias de mayor importancia). El otro es el que mide la extensión de la noticia en páginas interiores, excluyendo la portada y los artículos de opinión, referido a páginas completas del diario. Con estos indicadores hemos realizado una valoración descriptiva para conocer el funcionamiento temporal de la noticia, la magnitud máxima que alcanza y la pérdida de interés. Además, hemos complementado el estudio de los dos índices con un análisis textual semántico para estudiar el manejo de las fuentes de información en la catástrofe, comprobando todas las menciones que se han hecho a las informaciones de fuentes oficiales.

En segundo lugar, para captar la opinión de los participantes del proceso de comunicación e informativo aportamos las experiencias vividas por ocho profesionales que trabajaron en la cobertura del terremoto (Tabla 1). Dos de ellos estuvieron al frente de la comunicación pública institucional y seis fueron periodistas que cubrieron el desastre desde Lorca. Para realizar este análisis hemos transcrito las ponencias de la mesa "Gestión de la Comunicación y la Información" de la I Jornada Lorca Resiliente "Lecciones aprendidas del terremoto", celebradas en Lorca (Murcia) del 26 al 28 de noviembre de 2014. La transcripción total generó un corpus de 19 páginas con 9.070 palabras analizadas para poder extraer conclusiones importantes sobre las prácticas periodísticas durante la cobertura de la catástrofe.

\begin{tabular}{|l|l|}
\hline \multicolumn{1}{|c|}{ Nombre } & \multicolumn{1}{c|}{ Empresa } \\
\hline Serafín Piñeiro Gallardo & Jefe de Prensa del Ayuntamiento de Lorca \\
\hline $\begin{array}{l}\text { Miguel Ángel Pérez } \\
\text { Heredia }\end{array}$ & $\begin{array}{l}\text { Director General de Comunicación de la Comunidad } \\
\text { Autónoma de la Región de Murcia (2008-2015) }\end{array}$ \\
\hline Lázaro Giménez Cáceres & Periodista de Radio Lorca-Cadena SER \\
\hline Antonio Díaz Montoro & $\begin{array}{l}\text { Periodista de la cadena de radio COPE y la agencia } \\
\text { EFE }\end{array}$ \\
\hline María del Pilar Wals Rúa & Periodista del diario La Verdad \\
\hline Nacho Gómez & Periodista de 7RM, la televisión autonómica de Murcia \\
\hline José Luis Martín Vadillo & Periodista de elmundo.es \\
\hline Juan Antonio De Heras & $\begin{array}{l}\text { Decano del colegio oficial de periodistas de la región } \\
\text { de Murcia }\end{array}$ \\
\hline
\end{tabular}

Tabla 1. Profesionales analizados para el artículo. Fuente: elaboración propia

Consideramos relevante rescatar este material generado en la jornada porque las actas del congreso no han sido publicadas y creemos que aporta gran valor al campo estudiado.

\section{EL TRATAMIENTO INFORMATIVOS DEL TERRAMOTO EN EL PAÍS Y EL MUNDO}

\subsection{Ciclo de la noticia en portada}

Como observamos en el Figura 1, la noticia adquiere mayor importancia al día siguiente del terremoto, el 12 de 
mayo de 2011, ocupando la información en portada un $42,2 \%$ en El País y un $28,6 \%$ en El Mundo. Alcanza su máximo el segundo día, el 13 de mayo, en ambos diarios (47\% en El País y 31,2\% en El Mundo) para prácticamente desaparecer al quinto día, el 16 de mayo. El sexto día reaparece con una presencia casi irrelevante en la portada de ambos periódicos (3,2\% y $2,2 \%)$.

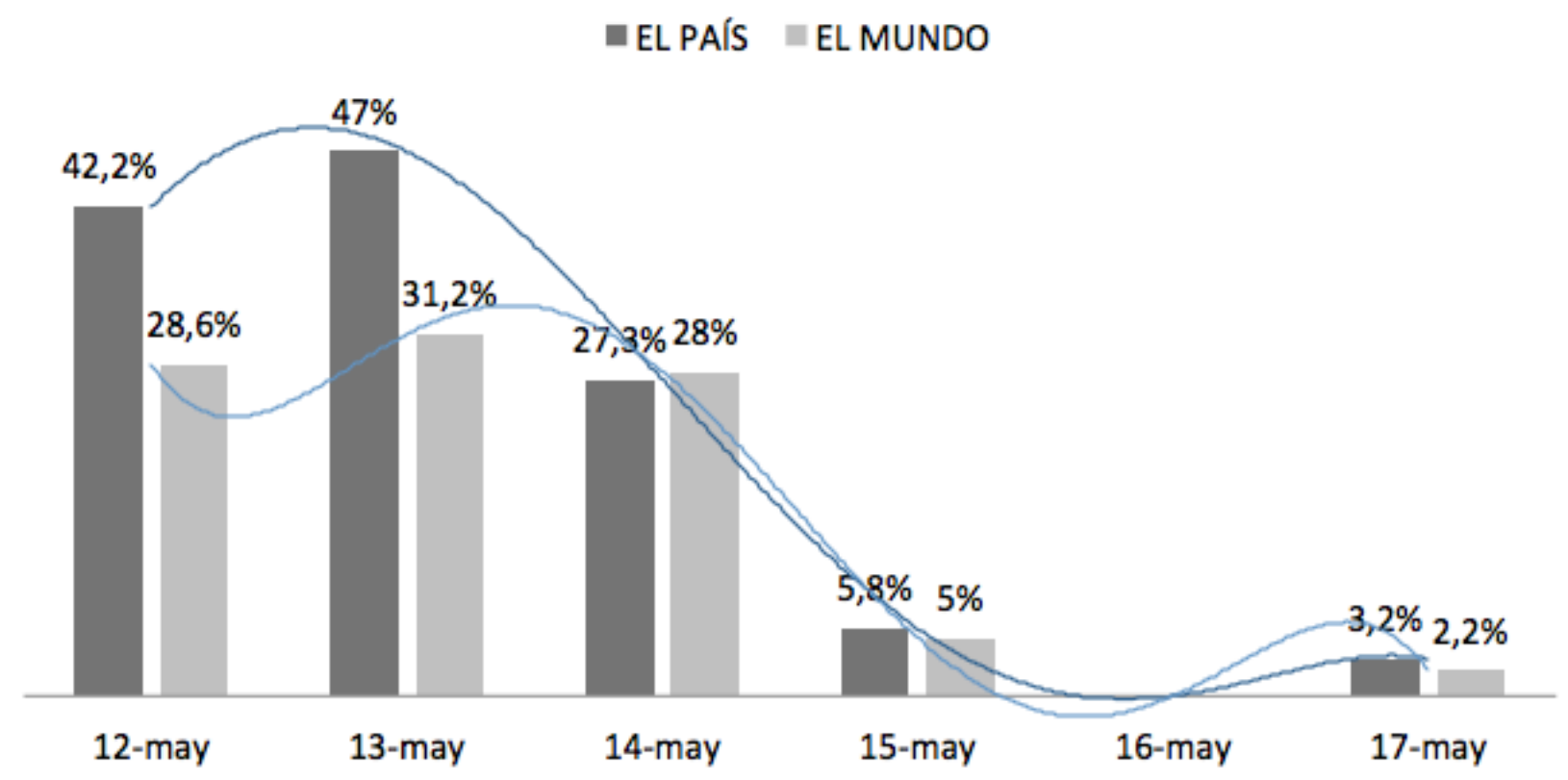

Figura 1. Superficie en portada dedicada al terremoto de Lorca. Fuente: elaboración propia

Si hacemos el promedio de todos los porcentajes, El País obtiene un $20.9 \%$ de superficie en la portada durante los días de análisis frente al $15.8 \%$ de El Mundo (en este resultado se incluye el día 16 de mayo con un $0 \%$ ). Por su parte, las líneas de tendencia muestran que la cobertura mediática del terremoto de Lorca tuvo prácticamente su fin después del cuarto día.

En cuanto a las portadas en sí, El Mundo y El País emplearon la misma imagen para ilustrar la portada del día posterior al desastre, el 12 de mayo. La foto muestra la hija de uno de los fallecidos a causa del seísmo (Figura 2). La mujer es consolada por una agente municipal y varios vecinos en la calle Galicia de Lorca. El Mundo decidió recortar la imagen para no mostrar el cadáver que yace entre los escombros. A diferencia de El País en el que sí se ve el cadáver. Es una foto descriptiva con mucha potencia informativa que transmite perfectamente el horror de la tragedia. 


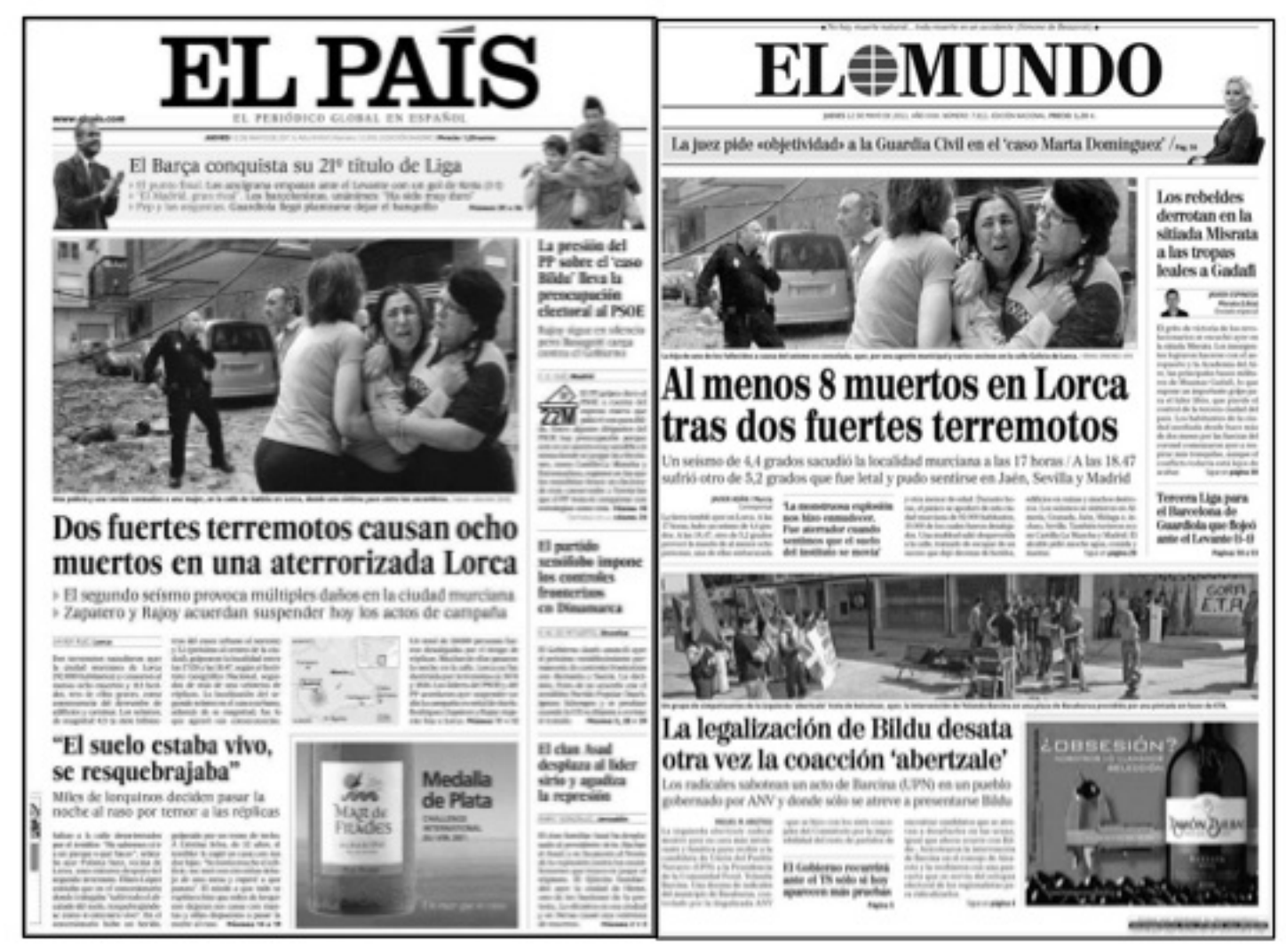

Figura 2. Portadas de El País y El Mundo del 12 de mayo de 2011. Fuente: El País y El Mundo

Para medir el impacto de la noticia hay que situarla en contexto. El día anterior el Fútbol Club Barcelona empató su partido con el Levante y se proclamó campeón de Liga. El día 12 la noticia era portada en todos los diarios. El terremoto relegó la noticia deportiva a un segundo plano. Además del contexto futbolístico, había un contexto político, ya que a finales de mayo se celebraban las elecciones autonómicas y municipales. Los medios de comunicación siempre dedican una gran cobertura mediática a las campañas electorales y esta era especialmente relevante por varios hechos: la profunda crisis económica mundial, el debate interno en el que estaba sumergido el PSOE para encontrar sucesor del presidente Zapatero y el posible vuelco electoral en tradicionales bastiones de los socialistas como eran Castilla La Mancha y Extremadura.

\subsection{Ciclo de la noticia en páginas interiores}

El mayor número de páginas completas dedicadas al terremoto se alcanza, como podemos observar en el Figura 3 fue dos días después del terremoto (13 de mayo) con 8.7 páginas en El País y 7.4 en El Mundo. El día 12, una jornada después de la tragedia, se presentó una información de urgencia, sin tiempo para la reflexión, teniendo en cuenta además que los temblores se produjeron a media tarde (17:05 hora local el primero). Aunque El País otorgó más relevancia a la noticia en la portada, si sumamos el número de páginas totales dedicadas a la cobertura del desastre, observamos que los dos diarios dedican prácticamente el mismo número de páginas a la catástrofe (El País un total de 22,5 páginas y El Mundo, 22,2).

Si cruzamos los datos, observamos cómo El País lidera la cobertura alcanzando mayores registros que El Mundo todos los días. En el interior del diario las curvas se invierten como apreciamos en las líneas de tendencia. El País dedica más páginas los dos primeros días, pero después es El Mundo, es el que pasa tener una mayor cobertura periodística de la tragedia. 


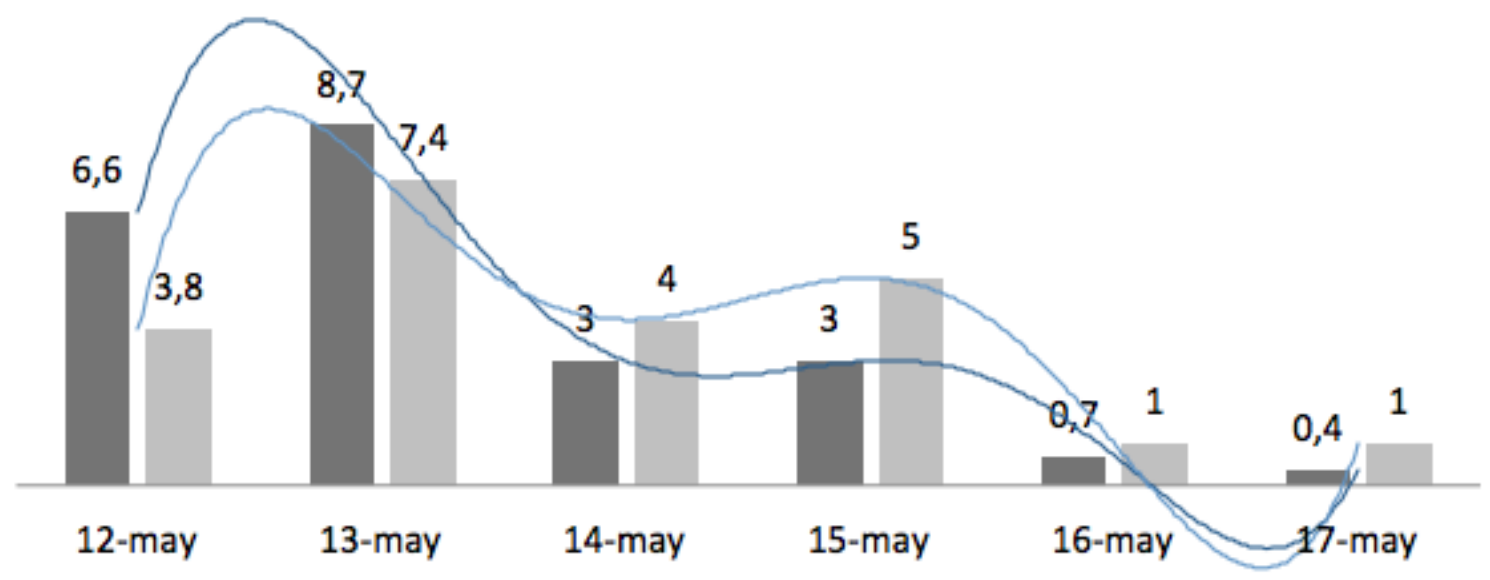

Figura 3. Número de páginas dedicadas al terremoto de Lorca. Fuente: elaboración propia

Creemos relevante destacar en el apartado de resultados, la presencia de informaciones relacionadas con el terremoto en casi todas las secciones del diario. Por ejemplo, el día 13 de mayo, El Mundo dedica una página y media más a la cobertura del seísmo aprovechando la presencia del estand de Lorca en la Feria Internacional del Turismo (Fitur) que se celebraba esos días en Madrid. La sección de local, en este caso de la edición madrileña, dedicó una información a este hecho. El día 16, encontramos otro ejemplo sobre cómo las catástrofes dotan de relevancia a noticias de escasa transcendencia de manera indirecta. Esa jornada El Mundo le dedicó una pequeña mención al equipo de fútbol de la localidad de Lorca, titulándola "El Lorca se salva del descenso a Segunda División B gracias a un empate a dos".

En la Figura 4 cuantificamos el número de artículos publicados al día en cada cabecera durante el periodo comprendido entre el 12 y el 17 de mayo de 2011. Como hemos explicado en la metodología el corpus analizado ha sido de 91 artículos, de los que 42 se corresponden a El País y 49 a El Mundo.

\section{"EL PAÍS EL MUNDO}

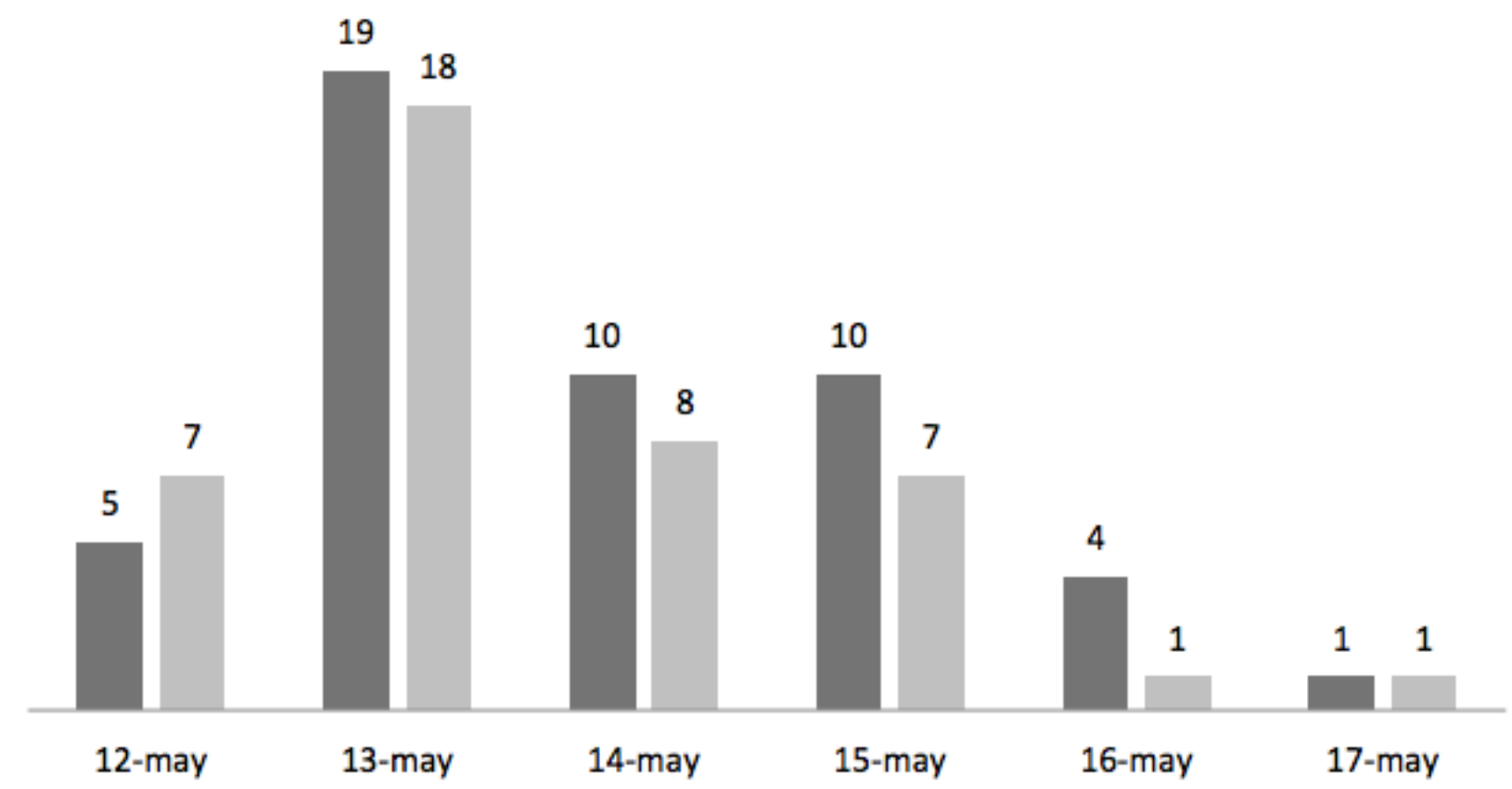

Figura 4. Número de artículos analizados por día. Fuente: elaboración propia 
Observamos en la Figura 4 que el número de noticias por día alcanza su máximo en la segunda jornada posterior al terremoto (37 informaciones, 19 en El País y 18 en El Mundo). Luego se produce una estabilización los dos días siguientes para reducirse a una solo una información en cada periódico a partir del quinto día de análisis.

\subsection{Análisis textual semántico de las noticias}

La primera información que aparece en el diario El País el día después de la catástrofe: "El Ayuntamiento activó el Plan de Emergencias Municipal y el Gobierno murciano puso en marcha el nivel 2 del Plan de Emergencias ante el Riesgo Sísmico de la Comunidad Autónoma de Murcia (SISIMUR). Todos los servicios de emergencias quedaron activados" (Calleja, 2011), corresponde a un comunicado de prensa enviado a todos los medios por el gabinete de prensa del Plan de Emergencias. Esto demuestra que la información oficial es siempre prioritaria para los medios de comunicación a la hora de elaborar sus noticias. También podemos leer en El Mundo: "El Ministerio del Interior tuvo que constituir anoche el Comité Estatal de Coordinación del Plan Sísmico y declarar el nivel 2 de emergencias" (Altozano y Sanz, 2011).

El presidente del Gobierno, en ese momento, José Luis Rodríguez Zapatero, calificó la gestión institucional de la catástrofe, incluida la labor comunicativa, como muy positiva: "la coordinación y la unidad de acción de todas las administraciones ante la catástrofe ha sido ejemplar" (Pérez, 2011). Pero la investigación de lbáñez (2014) que analiza todas las notas de prensa difundidas por los tres niveles de la Administración Pública durante el terremoto cuestiona la gestión comunicativa del desastre. Pone de manifiesto una descoordinación informativa, afirmando el que gabinete de prensa del SISMIMUR se comportó más como "una agencia noticias más, desde la que parece ser que incluso se suministraba vía Twitter y Facebook información de carácter institucional más que de emergencia" (Ibáñez, 2014: 330). Además hasta las 20:00 horas del día 11, el gabinete de prensa de la comunidad autónoma no emitió una primera nota de prensa y la primera vez que se convocó a los medios para informar sobre los datos que se tenían ya confirmados, no fue hasta las 21:00 cuando todos los informativos de televisión ya habían iniciado su emisión.

En la muestra analizada se ha detectado un error con un tema extremadamente delicado: la cifra de víctimas. La cifra de fallecidos es un trabajo capital para el gabinete de prensa o departamento de comunicación encargado de la gestión comunicativa de una catástrofe. La delegación del Gobierno, que había informado inicialmente de la muerte de 10 personas, rectificó horas después y rebajó la cifra a ocho (1). Este error refuerza la teoría sobre la descoordinación informativa entre las instituciones públicas que al final tiene reflejo en las coberturas periodísticas de los medios de comunicación.

Es evidente la falta de coordinación y la improvisación de los distintos actores (administración central, autonómica y local) involucrados como la causa de este error mayúsculo. Según lbáñez (2014) no se gestionó la comunicación según el Plan Estatal de Protección Civil ante el riesgo sísmico ni tampoco el Especial antes el riesgo sísmico en la región de Murcia. Por lo que al no activarse ningún Plan de Comunicación, la población afectada no reaccionó correctamente al desconocer las medidas de autoprotección y como consecuencia, esta falta de información pudo ser la causa de muchos de los daños de esa catástrofe.

Otra causa de ello, fue que en el terremoto de Lorca encontramos la fórmula de múltiples portavoces (el alcalde del municipio, el presidente del Gobierno, de Murcia, el ministro del Interior y portavoz del Gobierno, Alfredo Pérez Rubalcaba, además de los portavoces de los distintos equipos que participaron en la emergencia), algo que incrementó la descoordinación porque muchas veces los mensajes institucionales eran contradictorios.

En los dos medios analizados se hace referencia a la coordinación del operativo y el centro de mando: "Este despliegue permanecía anoche dirigido por un comité operativo con sede en Murcia y otro de seguimiento en Madrid" (Ruiz, 2011). "Todos ellos se introdujeron en el camión que hacía las veces de centro de mando y que entre miembros del Gobierno de tres administraciones, de la oposición, de asesores y de jefes de gabinete parecía el camarote de los hermanos Marx" (Adán, 2011). Pero sorprende que un tema de profundo interés periodístico y también para la audiencia, que es el saber cómo se ha gestionado técnicamente el desastre, no ha sido desarrollado en profundidad por ninguno de los dos diarios.

Uno de los personajes claves en la respuesta a la emergencia fue el Director del Plan de Emergencias, 
fundamental a la hora de narrar el relato del desastre, pero sólo hemos observado una pequeña aparición en El País.

Otra imprecisión que hemos detectado en nuestro estudio son las magnitudes de los dos terremotos. Ambos coinciden en las horas 17:05 y 18:48 pero el El País habla de 4.5 y 5.1 de magnitud y El Mundo 4.4 y 5.2a pesar de citarlos dos como fuente al Instituto Geográfico Nacional. Al día siguiente, el 13 de mayo, El País rectificó a magnitud 5.2, mientras que El Mundo la cambió a 5.1 para el 14 de mayo, volver a señalar que la magnitud era de 5,2 en la escala de Richter. Este baile de cifras, que despista al lector, se podría haber evitado si se hubiera empleado dos únicas magnitudes oficiales facilitadas por el gabinete de prensa del Instituto Geográfico Nacional como fuente autorizada.

Hemos observado que es bastante frecuente que los medios engloben las noticias referidas al desastre bajo un título único que las dote de homogeneidad y continuidad. El Mundo decidió agrupar todas las informaciones bajo un especial titulado "Murcia tiembla". Mientras que El País eligió "Seísmo mortal en Murcia".

\section{ANÁLISIS DE LA EXPERIENCIA DE LOS PROFESIONALES DE LA INFORMACIÓN}

Tras codificar las ponencias de los ocho profesionales que trabajaron durante el terremoto de Lorca, podemos hacer el siguiente análisis.

\subsection{Las primeras 24 horas}

Serafín Piñeiro, jefe de prensa del Ayuntamiento de Lorca, asegura que el terremoto fue un curso acelerado de empatía social para todos: periodistas, técnicos, víctimas, etc. Recuerda como el seísmo "nos enseñó a trabajar con lo mínimo, a comunicar con lo puesto y a adaptarnos a la situación de forma rápida y efectiva". Afirma que durante las primeras 24 horas la estrategia informativa se centraba en las constantes intervenciones del alcalde que se realizaban cada 10 minutos, que permitían "satisfacer la demanda de información de los propios ciudadanos, ofreciendo de forma rápida y directa las noticias de las decisiones que se iban adoptando y los datos de la emergencia" (Piñeiro, 2014).

El director de comunicación de la Región de Murcia, Miguel Ángel Pérez (2014), explica que en San Esteban, la sede de la Dirección de Comunicación del gobierno regional, a los pocos minutos ya tenía los primeros mensajes de los servicios de emergencia de la Comunidad. Acudieron todos los periodistas que trabajan en las distintas consejerías, se distribuyó el trabajo y se elaboró un primer gabinete de crisis en la primera media hora. En las primeras 24 horas recibieron más de 40 solicitudes de entrevista.

Lárazo Giménez (2014), periodista de la Cadena SER, también considera que los periodistas supieron reaccionar con profesionalidad y compromiso ante la emergencia social e informativa. Antonio Díaz Montoro (2014), periodista de la COPE y EFE explica que las primeras crónicas tras los terremotos eran puramente descriptivas, fruto de la observación, porque apenas minutos después no tenían ni siquiera información precisa de la magnitud del seísmo. Asegura que el caos de la calle en ese momento era una fuente inagotable de argumentos informativos y que no se cayó en la tentación de magnificar, porque la tragedia ya era grave de por sí y que se trabajó de urgencia "para que el mensaje llegara lo más lejos posible y además fuera eficaz, comprensible y riguroso".

Nacho Gómez (2014), editor y presentador de 7RM, afirma que se hizo un despliegue sin precedentes con un especial informativo de casi 9 horas que después merecería el premio IRIS de la Academia de las Artes al mejor programa informativo. Explica que hubo que dar un vuelco a la parrilla y coordinar a un equipo de 60 redactores. Además comenzaron a recibir llamadas de televisiones, generalistas y autonómicas, para pedir imágenes y contenidos. También medios internacionales como CNN y la BBC.

José Luis Martín Vadillo (2014), jefe de sección de El Mundo, explica que en su trabajo gestionan la información de últimas noticias. Así que las tragedias y desastres son uno de sus principales focos de atención. Afirma que el terremoto de Lorca fue uno de los pocos acontecimientos que se pudo ver en directo. Explica que las fuentes en los acontecimientos de última hora es la presencia in situ de los profesionales de la información, el envío de 
corresponsales o llamadas telefónicas con testigos directos e indirectos.

\subsection{Las fuentes oficiales}

Serafín Piñeiro (2014), jefe de prensa del Ayuntamiento de Lorca, explica cómo el contenido de las intervenciones se actualizaba a medida que llegaba informaciones de distintas fuentes (trabajadores del ayuntamiento, 112, responsables públicos, etc.). Indica que de esta forma se construía un discurso claro, breve y sencillo que aclarara las dudas que los ciudadanos tenían: cómo estaba la situación y cuándo podrían regresar a sus viviendas. El director de comunicación de la Región de Murcia destaca la labor de coordinación informativa entre todas las administraciones e instituciones públicas involucradas en la respuesta. En las primeras 24 horas el gabinete de prensa contó con más de 200 llamadas de medios de comunicación España pero también de medios como France Press o el Washington Post, etc. Se elaboraron comunicados de prensa a través de un único portavoz que difundía las novedades cada 2 o 3 horas, realizándose 9 partes en 24 horas según Miguel Ángel Pérez (2014).

Lázaro Giménez, periodista de la Cadena SER, recuerda que había que priorizar los contenidos necesarios para los ciudadanos ante la catástrofe procedentes de fuentes oficiales. Es decir, informar sobre las estructuras dañadas, el número de atención a los afectados, la ubicación de los campamentos, las vías de evacuación, etc. También Antonio Díaz, periodista de la COPE y de la Agencia EFE explica que se le reclamaba centrar la cobertura de la noticia en información precisa y verificada con fuentes fehacientes y que eludiera la espectacularización de la catástrofe.

Nacho Gómez (2014), de 7RM TV, sugiere que en cuanto al flujo de la información desde fuentes oficiales y de cara al futuro para mejorar la comunicación institucional con los medios podría crearse una aplicación móvil o habilitar cuentas en redes sociales para suministrar información en tiempo real con geolocalización por GPS.

Una figura esencial en la comunicación pública institucional para capitalizar la difusión de la información es la del portavoz único. El objetivo es difundir un único mensaje, evitar la descoordinación y acallar los rumores generados en este tipo de situaciones (Mayo, 2011). El portavoz del Ayuntamiento de Lorca fue su alcalde, Francisco Jódar, que realizó, según el Consistorio, intervenciones cada 10 minutos. El jefe de Prensa del Ayuntamiento le define como "un buen comunicador, reconocido, cercano y con capacidad para mantener la serenidad en unos momentos especialmente difíciles” (Piñeiro, 2014).

Desde la Dirección de Comunicación autonómica explican que se realizó una estrategia comunicativa integral para que Lorca no desapareciera de la agenda de los medios en la etapa tras la crisis. Todos los viernes, el portavoz del Gobierno iniciaba la rueda de prensa con noticias de la reconstrucción. También se decidió celebrar el Consejo de Gobierno del 12 de mayo de 2011 en Lorca para conmemorar el aniversario de la tragedia.

Las lecciones aprendidas de la gestión en la etapa poscrisis sugieren que la comunicación pública institucional debe esforzarse por mantener la atención de los medios para que la catástrofe no desaparezca de la agenda mediática.

\subsection{El uso de redes sociales tras el terremoto}

El jefe de prensa del Ayuntamiento de Lorca recuerda que ante el apagón de recursos informáticos, recurrieron al método tradicional de impresión y reparto de folletos con los consejos fundamentales, incluyendo un código de colores sobre el estado de los edificios que tuvo un rendimiento especialmente positivo. Más adelante cuando se solucionaron las conexiones se recurrió al uso de las redes sociales, en especial Facebook para informar a los ciudadanos, pero sólo para consolidar la difusión de los mensajes más importantes (Piñeiro, 2014).

Para Giménez (2014) el terremoto de Lorca fue la primera gran catástrofe en España contada a través de redes sociales. Afirma que era el momento de eclosión de fenómenos como Facebook y Twitter: el temblor ocurrió el 11 de mayo y cuatro días después cristalizaría un movimiento como el $15 \mathrm{M}$ que ya se estaba germinando en Internet los meses previos. 
De la gestión en redes sociales de las últimas tragedias y catástrofes ocurridas en España, el jefe de la sección "Última hora" de Elmundo.es, José Martín Vadillo, ha sacado cinco conclusiones:

1. Las redes sociales se han convertido en una herramienta imprescindible para la gestión de las noticias de última hora.

2. Es imprescindible comprobar siempre el origen de la información, las cuentas de las redes sociales y los perfiles de los que procede. Si no el periodista corre el riesgo de convertirse en un usuario más y dejar de hacer periodismo.

3. Es muy importante hacer una doble verificación de las fuentes con los usos propios del periodismo tradicional.

4. La red da la oportunidad de llegar cada vez a más puntos informativos y con mayor rapidez. Sobre todo, cuando los desastres ocurren en zonas muy alejadas, de difícil acceso, aunque sea en España.

5. En las redes sociales el rol del periodista es más importante que nunca siempre que prime la responsabilidad informativa. Sobre todo, en estos tiempos de recortes, en los que las empresas dicen que ya no es necesario ir al lugar de los hechos o tener gente especializada, que basta con extraer información de aquí para colocarla allá (Martín, 2014).

Desde la dirección de comunicación autonómica se activaron las redes sociales a través de www.noticias.car para informar del parte de heridos, de la situación de los colegios, centros de salud, etc. El director reconoce que "fue una herramienta estratégica muy importante y con mucha actividad" (Pérez, 2014).

\subsection{La cobertura periodística minutos después del terremoto}

En las catástrofes, se da la particularidad de que los periodistas también pueden ser víctimas. "En los primeros momentos, muchos de los periodistas no sabían si sus casas estaban dañadas y tampoco podían localizar a sus familiares" (Piñeiro, 2014). Esa doble condición, provoca un dilema para el periodista sobre atender primero lo personal o lo profesional: "Hubo que sobreponerse en muy pocos minutos de la tragedia personal para contarle al público una noticia de la que también éramos noticia. Es muy duro ponerse atrabajar en medio de una catástrofe sin saber qué ha pasado con tu familia, tus amigos y tu casa" (Díaz, 2014).

A Giménez, como a muchos ciudadanos el terremoto le pilló por sorpresa en la calle. El periodista de la SER afirma que automáticamente después del primer terremoto todos acudieron a la emisora, salieron con sus grabadoras, micrófonos y bolsas de Radio Lorca para trabajar porque no sabían si iban a poder volver.

Ma Pilar Wals del diario La Verdad recuerda a posteriori los errores cometidos llegando a arriesgar su vida para informar: "Cometimos muchas imprudencias, lo hicimos desde el minuto cero, al no abandonar la delegación de La Verdad tras el primer terremoto. Poco después nos echamos a la calle y a punto estuvimos de protagonizar las crónicas más negras, ya que el segundo terremoto pilló por sorpresa a parte del equipo de redactores en el Convento de San Francisco que sucumbió segundos después" (Wals, 2014).

\subsection{La falta de especialización periodística en catástrofes}

Los periodistas que cubrieron el terremoto de Lorca coinciden al señalar que no estaban especializados ni formados en lo que les iba a tocar cubrir, pero afirman que supieron reaccionar con profesionalidad y compromiso a la emergencia informativa. Wals (2014) asegura que "no había precedentes ni un plan predeterminado para actuar en una situación de tal calibre. Nunca antes se había vivido una catástrofe de tal magnitud, no sólo en la región sino en todo el país". Desde su experiencia, Giménez (2014) opina que la falta de formación no es una laguna en la etapa universitaria, sino que la capacitación debe venir después. Díaz (2014) destaca la necesidad de impulsar Congresos, Jornadas e investigaciones en el campo de la comunicación de catástrofes para hacer autocrítica y extraer lecciones que sirvan para el futuro en esta especialización del periodismo.

\subsection{Sensacionalismo}

Aunque para Serafín Piñeiro ha prevalecido el trabajo periodístico bien hecho, el jefe de prensa recuerda 
episodios nada edificantes, de un amarillismo exacerbado y lo compara con la comida rápida: "No podía faltar la pieza periodística exprés, de pésima calidad y nula aportación” (Piñeiro, 2014). Añade que, a su juicio, uno de los capítulos más tristes en este sentido fueron los rumores que se difundieron sobre cómo los lorquinos estaban utilizando los recursos procedentes de donaciones y eventos benéficos, que en algunos casos se afirmó que se utilizaba para pagar el sueldo a los funcionarios municipales. Según Piñeiro, la consecuencia directa de esa mala información, fue que las aportaciones se frenaron súbitamente provocando incluso la cancelación de eventos benéficos que se tenían previsto celebrar (Piñeiro, 2014). El Gabinete de Prensa del Ayuntamiento reaccionó de forma inmediata facilitando a los medios de comunicación, una lista con las aportaciones y su destino, además de añadir los criterios para recibir estas ayudas. También la página web del Ayuntamiento publicó tanto las aportaciones que se iban recibiendo y los movimientos como el saldo de las cuentas solidarias. Todo ello se reforzó estableciendo una rueda de prensa semanal para informar directamente a la prensa (Piñeiro, 2014).

Nacho Gómez reflexiona sobre el límite de la imagen en los desastres y opina que las imágenes dantescas de la tragedia tienen un efecto negativo en el ánimo de los afectados cuando se emiten una y otra vez, simplemente para ilustrar una actualización de la noticia: "Si hacemos esto estamos convirtiendo todo en un espectáculo. En la televisión siempre pensamos qué es lo que le gusta a la audiencia, a la gente, y muchas veces acabamos cayendo en el morbo" (Gómez, 2014).

También Giménez (2014) reconoce que se huyó del papel "periodista-protagonista" a pesar de que un hecho así les ponía en el foco de la noticia, pero que no se debe caer en el "sensacionalismo, el amarillismo, el periodismo lacrimógeno".

\section{7. Ética y deontología}

Díaz (2014) considera que en los últimos años las universidades, colegios profesionales y diversas instituciones se han ocupado del tratamiento informativo de las catástrofes. En un intento corporativo de sistematizar el trabajo de los periodistas se han desarrollado varios códigos sobre la cobertura responsable de desastres naturales. El periodista de la COPE y la Agencia EFE expone que en esa situación límite se mezcla la tensión del momento, la urgencia informativa y fuentes muy diversas supervivientes, políticos, autoridades, expertos, militares, etc.

Nacho Gómez (2014) considera que la autorregulación es un ejercicio de libertad periodística y no de manipulación. Afirma que los medios pueden aportar serenidad y "contribuir a cerrar las heridas psicológicas destacando aquellos comportamientos heroicos, solidarios y esperanzadores. La denuncia social para mover la solidaridad y sobre todo la acción de los gobiernos" (Gómez, 2014). También recuerda que hay que tener especial cuidado al grabar imágenes para no vulnerar la privacidad de los afectados. En opinión del editor y presentador la eliminación de imágenes escabrosas no resta información a la tragedia y no es una limitación al derecho a estar informado.

La Asociación de la Prensa de Madrid (APM, 2014) ha publicado nueva pautas acerca de cómo informar adecuadamente en las catástrofes: la información no debe desfigurarse; no hay que dramatizarla; hay que hacer una separación clara entre información y opinión; no hay que crear falsas alarmas o falsos culpables; hay que cuidar el lenguaje utilizado para aportar serenidad a los afectados; hay que extremar la cautela en la identificación de las víctimas para que la noticia llegue a los familiares por los canales oficiales y no por los medios; y no hay que utilizar estas informaciones para aumentar la audiencia.

El rumor es el principal enemigo en la gestión comunicativa de la catástrofe generando situaciones de alarma totalmente innecesarias. Por ello, Serafín Piñeiro, jefe de prensa del Ayuntamiento de Lorca, afirma que monitorizaban continuamente las informaciones que iban apareciendo en la prensa, para detectar las informaciones falsas y atajarlas de forma rápida y efectiva (Piñeiro, 2014).

Desde la perspectiva de los medios, Nacho Gómez opina que contrastar la información con las autoridades y los técnicos reducen los errores y el alarmismo y pone un ejemplo: "Aquellos primeros días dijeron que habría réplicas de menor intensidad durante al menos dos meses. Creo que la primera semana fueron 113 réplicas aquí en Lorca. Estos mensajes de expertos reducían la histeria” (Gómez, 2014). 


\subsection{Responsabilidad social periodística}

La responsabilidad social es crucial en el rol del periodista como fiscalizador de la gestión política del desastre. Díaz (2014) opina que la progresiva vuelta a la normalidad tras el impacto, no puede llevar a la autocomplacencia. El periodista debe velar por el cumplimiento de las tareas encomendadas a la Administración Pública: asistencia, protección, reconstrucción, etc. Debe dar voz a los damnificados y visibilizar situaciones que algunos tratan de ocultar. La especulación de los alquileres, la precariedad de los campamentos, las reclamaciones por las promesas incumplidas de la Administración Pública, los bancos exigiendo el pago de hipotecas por casas derruidas o los actos aislados de pillaje son parte de esa realidad incómoda que el periodista tiene la obligación de narrar (Díaz, 2014).

El periodismo responsable puede servir también para recuperar emocionalmente a la comunidad afectada: alimentando su capacidad de resiliencia con informaciones que visibilicen la humanidad, la solidaridad y los comportamientos heroicos (Gómez, 2014). Quizás el mejor ejemplo de esa capacidad de resiliencia, se vio en Lorca el día22 de mayo 2011, cuando los ciudadanos fueron a votar para las elecciones autonómicas en colegios electorales habilitados bajo carpas y con las calles llenas de escombros y de edificios apuntalados.

\section{CONCLUSIONES}

Tras la exposición de los resultados relacionados con la aparición de noticias sobre el terremoto de Lorca en El País y El Mundo confirmamos la teoría de Hodgkinson y Stewart (1991) que asegura que el ciclo de vida de este tipo de noticias de gran impacto tiene una duración aproximada de 5 días. En nuestro estudio, comprobamos que se repite ese patrón: gran impacto el primer día con un interés creciente el segundo día (según el número de páginas completas como de la superficie de portada) para caer en picado el quinto día de cobertura (Figura 1). Es reseñable que el día que más cobertura se hace del terremoto en la prensa no es el día después sino tras la segunda jornada y creemos que esto se debe a que es el momento en el que los medios conocen ya con mayor exactitud la magnitud de la tragedia.

Por otro lado, a pesar del ciclo de vida del impacto durante 5 días, observamos dos aspectos destacables en los medios analizados: las noticias sobre el terremoto se expandieron por todas las secciones de los diarios y desplazaron grandes acontecimientos como las elecciones inminentes y el triunfo de la liga del Barcelona. Es decir, podemos deducir que las catástrofes y desastres adquieren una relevancia capaz de desplazar de la portada al campeón de Liga, en un país en el que el fútbol genera un interés informativo mayúsculo. Pero además se hicieron referencias al terremoto en secciones como la de deportes donde se prestó especial atención al equipo de fútbol de Lorca. Evidentemente, sin el terremoto esta noticia nunca hubiera publicado en el diario.

Entre otras conclusiones, hemos podido comprobar que el periódico El País dio más importancia porcentual al terremoto de Lorca en portada que El Mundo. Sin embargo, a pesar de las líneas editoriales antagonistas, ambos diarios otorgan a la cobertura de la catástrofe proporcionalmente una relevancia similar, más homogénea en el caso de El Mundo con porcentajes alrededor del 30\% los tres primeros días.

En cuanto al análisis del contenido de las informaciones, el ciclo de la noticia se mantuvo con la polémica sobre la calidad de las construcciones de los edificios en Lorca y sobre si realmente se habían tomado las medidas necesarias de seguridad al construirlos. Los dos medios analizados también se centraron en las tareas de reconstrucción y en las indemnizaciones. Es precisamente en estos temas donde, en mayor medida, los medios de comunicación pueden hacer valer su responsabilidad social con la audiencia.

También creemos reseñable la opinión de los ocho profesionales captadas en este trabajo. Por ejemplo, concluimos que la cobertura periodística del terremoto fue bastante imprecisa en gran parte por la descoordinación que hubo entre los gabinetes de prensa institucionales. Desde el punto de vista comunicativo, la información durante una catástrofe o desastre debe pivotar sobre el servicio público. La información no debería ser alarmista ni sensacionalista ni basada en rumores. Son tres pautas básicas y esenciales que deberían guiar todas las informaciones responsables. También la responsabilidad social del periodista debe 
manifestarse en la fiscalización de la gestión política del desastre durante la fase aguda, pero aún más en la fase poscrisis (por ejemplo, cuando llegan los fondos destinados a la reconstrucción). La autorregulación y el cumplimiento de los códigos éticos podrían limitar esos comportamientos irresponsables, pero se observa una deficiente labor divulgativa de las instituciones en este sentido. La tragedia de Lorca ha sido la primera catástrofe en España narrada a través de Internet. La experiencia de esta cobertura nos sugiere que, en el caso concreto de la información surgida de las redes sociales, es fundamental comprobar el origen de las cuentas y de los perfiles de procedencia. En este sentido, también es esencial para el periodista realizar una doble verificación, en la que los usos tradicionales del periodismo, adquieren aún más significado.

Coincidimos con las conclusiones de Duhe (2008) cuando, en su estudio sobre los planes de emergencia de la prensa y las televisiones regionales durante el huracán Katrina, afirma que la gran mayoría de los medios analizados (el 64\%) no tenía elaborados planes para trabajar en situaciones de catástrofe (y en los pocos casos en los que existía un protocolo de actuación era muy limitado y de pobre calidad). Por tanto, desde nuestra perspectiva, consideramos que la introducción de asignaturas relacionadas con la materia en los planes universitarios complementaría la formación y mejoraría la capacitación de los futuros periodistas, al tiempo que les descubriría una novedosa y área de especialización, diferente de las tradicionales, pero con mucho potencial de crecimiento.

\section{REFERENCIAS BIBLIOGRÁFICAS}

ADÁN, J. (2011): "No es normal que un edificio nuevo se viniera abajo". El Mundo (13 de Mayo de 2011), p. 6.

ALTOZANO, M. y SANZ, O. (2011): "Dos terremotos sacuden Lorca con al menos 8 muertos". El Mundo, (12 de Mayo de 2011), p. 4.

APM. (2014): Nueve pautas que debe seguir un periodista para informar sobre catástrofes. Madrid: Asociación de la Prensa de Madrid.

ARCOS, P: Los desastres y su evolución conceptual y epidemiológica. En AA. VV. (2015): III Jornadas internacionales Periodismo en crisis, emergencias y desastres. Madrid: Universidad Carlos III.

BOE (1980): Boletín Oficial del Estado (25 de Abril de 1980), p. 8967-8971. Disponible en:

https://www.boe.es/boe/dias/1980/04/25/pdfs/A08967-08971.pdf (consultado el 12 de Mayo de 2015).

CALLEJA, T. (2011): “El Gobierno central moviliza a la policía, la Guardia Civil y el Ejército", El País, (12 de Mayo de 2011), p. 11.

COVELLO, V.; SLOVIC, P. y VON WINTERFELD, D. (1986): "Risk communication: A review of the literature", Risk Abstracts, 3 (4), pp. 172-182.

CHATIER, J. y GABLER, S. (2001): Risk communication and government: Theory andapplication for the Canadian food inspection agency. Canadian Food Inspection Agency. Disponible en:

http://www.inspection.gc.ca. (consultado el 18 de mayo de 2016).

DE PABLOS, J. y ELÍAS, C. (2003): "CSIC: chapapote de la ciencia española (o cómo se manipula información en catástrofes ecológicas)", Revista Latina de Comunicación Social (54).

DÍAZ, A.: Periodistas en el epicentro. Protagonista sin voluntarios de la noticia. En AA. VV. (2014): I Jornada Lorca Resiliente "Lecciones aprendidas del terremoto". Lorca.

DUHE, S. (2008): "Communicating Katrina: A Resilient Media", International Journal of Mass Emergencies and Disasters, 26 (2), pp. 112-127.

GARCÍA, E., y NICASIO, B. (2012): "La vigencia de los patrones clásicos de cobertura de las catástrofes naturales en la era de Internet”, Correspondencias y Análisis, 2, pp. 61-62. 
GIMÉNEZ, L.: Última hora desde Lorca. Los medios de comunicación ante los terremotos de 2011: información y servicio público. En AA. VV. (2014): I Jornada Lorca Resiliente "Lecciones aprendidas del terremoto". Lorca.

GÓMEZ, N.: Los terremotos de Lorca a través de la televisión. Ejercicio de responsabilidad. En AA. VV. (2014): I Jornada Lorca Resiliente "Lecciones aprendidas del terremoto". Lorca.

GONZÁLEZ VILLARINY, N. (2008): La comunicación del riesgo en la prensa escrita. Un estudio del tratamiento informativo del naufragio del petrolero Prestige en los diarios El País y El Mundo. Tesis inédita. Madrid: Universidad Complutense, 2008.

HODGKINSON, P. y STEWART, M. (1991): Coping with catastrophe. A handbook of disaster management. Londres: Routledge.

IBÁÑEZ, Á. (2014): Comunicación, administraciones públicas y gestión de crisis y emergencias. Tesis doctoral inédita, Universidad Complutense.

- (2012): La Información Pública y la legislación en materia de Protección Civil y Emergencia, Derecom, 10, pp. 48-69.

KASPERSON, R. E., y STALLEN, P. J. (1991): Risk communication: the evolution of attempts. In Communicating risk to the public. Londres: Klower.

LARRONDO, A. (2006): "Del impacto mediático al olvido: la pérdida de interés noticioso como indicador de la deshumanización de los medios", Revista Latina de Comunicación Social (61). Disponible en: http://www.ull.es/publicaciones/latina/200612Larrondo.htm (consultado el 16 de junio de 2016).

LOPERA, E. (2011): Aproximaciones a la Comunicación del Riesgo desde los Ámbitos Académico, Institucional y Mediático de la Sociedad Actual, Informe Técnicos Ciemat (1243), 11, pp. 12 - 23.

LÓPEZ, D.: El mapa de las crisis, emergencias y desastres. ¿Qué está ocurriendo un día como hoy en el mundo? En AA. VV. (2015): III Jornadas internacionales "Periodismo en crisis, emergencias y desastres". Madrid: Universidad Carlos III.

LOZANO, C.: Periodismo de catástrofes: la actualidad informativa como fuente de incertidumbres. En MORENO, C. (2009): Comunicar los riesgos. Ciencia y tecnología en la sociedad de la información . Madrid: Biblioteca Nueva, pp. 231-248.

LOZANO, C.: Reflexiones en torno a la imagen de un petrolero partido en dos. Comunicación social y catástrofe del Prestige. En AA. VV. (2003): V Congreso de Periodismo Ambiental. Madrid.

MAYO, M. (2011): Gestión eficaz de la información en catástrofes y emergencias. El caso del Terremoto de Lorca. Trabajo de investigación para la obtención del DEA. Universidad Complutense, Madrid, 2011.

OTWAY, H. (1990): Communicating with the public about major hazards: Challenges for European Research. Communicating with the public about major hazards. Londres: Elsevier Applied Sciences.

ODRIOZOLA, J. (2011): "La construcción informativa de la catástrofe del Prestige: el abuso de las fuentes institucionales”. Análisi (44), pp. 77-92.

ORBE, I. (2012): Emergencias y medios de comunicación. Bilbao: Academia de Arkaute.

OYANEDEL, R. y ALARCÓN, C. (2010): “Una mirada al tratamiento televisivo de la catástrofe”. Cuadernos de Información (26), pp. 115-122.

PÉREZ, F. J. (2011): “7.500 lorquinos se quedan sin hogar”, El País, (14 de Mayo de 2011), p. 15.

PÉREZ, M. A.: Comunicación en situaciones de crisis. El caso de los terremotos de Lorca. En AA. VV. (2014): I Jornada Lorca Resiliente "Lecciones aprendidas del terremoto". Lorca. 
PIÑEIRO, S.: Lecciones del tratamiento informativo de una tragedia. EN AA. VV (2014): I Jornada Lorca Resiliente "Lecciones aprendidas del terremoto". Lorca.

PUY, A. y CORTÉS, B. (1998): Percepción social de los riesgos y comportamiento en los desastres. Madrid: Pirámide.

RODRÍGUEZ, P. y ODRIOZOLA, B. (2012): "Catástrofes y periodismo: el relato, los escenarios, las interacciones y las necesidades prácticas y psicológicas de todos los implicados". Estudios sobre el mensaje periodístico, 18 (2), pp. 577-594.

RUIZ, J. (2011): Lorca, magnitud 5,1: al menos 8 muertos. El País, (12 de Mayo de 2011), p. 12.

SANDMAN, P. (1994): Risk communication. Encyclopedia of the environment. Boston: Houghton.

SERRANO, L. (2013): 11M y otras catástrofes. La gestión de la comunicación en emergencias. Madrid: iRescate.

SLOVIC, P. y WEBER, E.U. (2002): Perception of risk posed by extreme events, Risk management strategies in an uncertain world. Nueva York: Palisades.

UNISDR (2011): A guide for journalists covering disaster risk reduction. Disponible en: http://www.unisdr.org/files/20108_mediabook.pdf (consultado el 13 de mayo de 2016).

VICENTE-MARIÑO, M. (2009): La cobertura televisiva de la crisis del Prestige. Agendas, encuadres y discursos en los noticiarios españoles. Tesis doctoral inédita, Universidad Autónoma de Barcelona.

WALS, M.P.: Un imperativo moral de combatir el olvido y preservarla memoria. En AA. VV. (2014): I Jornada Lorca Resiliente "Lecciones aprendidas del terremoto". Lorca.

(1) Según el último balance del Gobierno de Murcia se produjeron nueve muertos y 293 heridos. Una mujer falleció en el hospital por la gravedad de las heridas sufridas.

\section{BREVE SEMBLANZA DE LOS AUTORES}

Marcos Mayo es doctor por la Universidad Complutense de Madrid y redactor de La Sexta Noticias en el grupo Atresmedia. Este artículo pertenece a la línea de investigación que ha desarrollado para la elaboración de su tesis doctoral centrada en la cobertura informativa de catástrofes en los medios de comunicación.

Eva Lavín es doctora y profesora de la Universidad Camilo José Cela y ha sido productora de informativos y programas en La Sexta y Telecinco. Tiene un Máster universitario en administración, dirección y organización de empresa y un Máster en producción de cine y televisión. Su líneas de investigación se centran en la historia de la comunicación y el uso de nuevas tecnologías en comunicación.

Jorge Gallardo-Camacho es Doctor en Comunicación Audiovisual, Profesor Contratado Doctor en la Universidad Camilo José Cela y subdirector del programa de televisión Espejo Público (Antena 3 Noticias). Comenzó su carrera profesional en CNN (Atlanta, Estados Unidos) y obtuvo su doctorado con la primera tesis doctoral sobre YouTube en España. Su línea de investigación está centrada en la televisión, las audiencias y las nuevas tecnologías 
Ámbitos. Revista Internacional de Comunicación, n.35, edición de invierno, 2016-2017.

Recibido: 20/11/2016

Aprobado: 01/12/2016 